\title{
Carbon and energy footprint of electrochemical vinegar wastewater treatment
}

\author{
Emine Esra Gerek ${ }^{1, *}$, Seval Y1lmaz ${ }^{1}$, A. Savaş Koparal ${ }^{1}$, and Ömer Nezih Gerek ${ }^{1}$ \\ ${ }^{1}$ Anadolu University, Faculty of Engineering, 26555 Eskişehir, Turkey
}

\begin{abstract}
Electrochemical treatment of wastewaters that are rich in organic compounds is a popular method, due to its acidic nature that avoids biological treatment. In many cases, the pollution hazard is considered as the chemical oxygen demand (COD) from active carbon, and the success of the treatment is measured in terms of how much this specific parameter is reduced. However, if electricity is used during the treatment process, the treatment "itself" has manufacturing and operational energy costs. Many of the studies consider energy utilization as a monetary cost, and try to reduce its amount. However, the energy cost of the treatment also causes emission of carbon at the energy producing side of the closed loop. This carbon emission can be converted into oxygen demand, too. Therefore, it can be argued that one must look for the total optimal carbon efficiency (or oxygen demand), while reducing the COD. We chose a highly acidic wastewater case of vinegar production, which is a popular food product in Turkey, to demonstrate the high energy consumption and carbon emission problem of the electrochemical treatment approach. A novel strategy is presented to monitor total oxygen demand simultaneously at the treatment and energy production sides. Necessity of renewable energy utilization and conditions on process termination points are discussed.
\end{abstract}

\section{Introduction}

Treatment of wastewater is applied for eliminating biological or chemical hazardous materials. Toxicity or poisonous behaviors of contaminants obviously need careful treatment. There is a wide literature regarding various types of treatment methods that target various contaminants inside different media. A thorough classification of treatment strategies for different targets is presented in [11]. From this categorization and due to various other reports, it can be seen that electrochemical treatment is a popular method that is used particularly for food production wastewaters [1-4]. The pollution sometimes requires careful treatment of a particularly harmful material. However, in many cases, the hazard is considered as the chemical oxygen demand (COD) from active carbon inside the raw wastewater. Electrochemical process, therefore, targets the oxygen demanding active molecules inside the aqueous environment. Elimination of the oxygen demand from acidic environments, such as the vinegar wastewater, prohibits a successful utilization of

\footnotetext{
* Corresponding author: eegerek@,anadolu.edu.tr
} 
biological treatment tools. Similarly, various membrane structures sometimes quickly spoil in the acidic environment prior to a successful treatment. These observations leave the electrochemical approach as a reasonable alternative [1].

Unfortunately, the treatment process "itself" has manufacturing and operational energy costs. Electrical energy utilization during COD removal (via electrochemical treatment methods) causes emission of carbon at the energy producing side of the closed loop. Therefore, it can be argued that one must look for the total and optimal carbon efficiency, which reduces the COD of the wastewater up to such an extent that the emitted carbon (or consumed oxygen) due to the spent energy remains "worth" the treatment.

The energy efficiency regarding electrochemical treatment of food industry wastewaters is a relatively known issue [2-4]. Besides, several researchers have attacked the problem of energy efficiency for different wastewater types [5-7]. A distinct novelty of the proposed research here (as opposed to the parametric optimization approaches of the described literature survey) is the assessment of the overall electrochemical treatment process with a common denominator of oxygen demand (or carbon emission, thereof). For example, in [2], the researchers have investigated energy consumption in electrochemical treatment of sugar, fruit juice and whey production wastewater. They have concluded various electrical energy consumption levels at the end of experiments with several settings, including applied voltage, electrolyte concentration, wastewater concentration, etc., in terms of $\mathrm{kWh}$ energy required per COD in mass. Unfortunately, the oxygen demand equivalent of the utilized kWh electric energy was not evaluated and an overall COD was not proposed. In [3], an energy consumption estimation was performed and in [4], both the consumed energy and the reduction in COD was monitored as a function of time. Again, the consumed energy was not set at an equivalent oxygen demand figure to assess the overall efficiency. It was observed that the oxygen demand equivalent of the consumed electrical energy was not stated as an issue in other types of electrochemical wastewater treatment applications, either [5-7]. In [6, 7], very detailed analyses regarding the monetary costs of the plant installations and treatment runs were achieved for various cost parameters, including the electrical energy. But the oxygen demand cost of the generated electricity was not mentioned. In a recent study by the authors [8], the oxygen equivalent of the utilized electrical energy was briefly examined for the case of tannery wastewaters, which also contain a poisonous contaminant of chromium.

In this particular study, the proposed "oxygen equivalent" assessment strategy is researched through the electrochemical treatment of vinegar production wastewater, which is known to have a highly acidic nature. Vinegar is a popular product in Turkey, and due to the acidity of its waste, electrochemical processes are the most preferred and successful treatment methods $[9,10]$. In this work, parallel plate iron and iridium electrodes were selected as two alternatives for comparison. The treatment experiments were repeated several times at different electrical current densities $\left(\mathrm{mA} / \mathrm{cm}^{2}\right)$ and at various initial $\mathrm{pH}$ settings for the batch processes. Both the reduction in COD and the consumed electrical energy were monitored and recorded (as explained in the Materials and Methods section).

Unlike conventional papers which report the energy consumption in terms of the utilized kWh of electrical energy [2-7], this work converts the energy to the production level oxygen demand. The conversion is performed via averaging electric production plants throughout the country in terms of their $\mathrm{CO}_{2}$ emissions, and then by calculating the oxygen part of the required emission from the atomic mass ratios. For this part, the average $\mathrm{CO}_{2}$ emissions of electric generation plants are researched and it was observed that, as of 2012, the average $\mathrm{CO}_{2}$ emission is $0.534 \mathrm{~kg}$ per $\mathrm{kWh}$ in Turkey, and $0.600 \mathrm{~kg}$ per $\mathrm{kWh}$ in the USA [12]. These values correspond to only averaged grid values and in case the plant uses local and renewable energy sources, the following analysis gets invalid. 
Once the energy is converted to the oxygen demand, the COD reduction (at the treatment plant side) and oxygen demand (at the energy generation side) may be combined as an "overall oxygen demand" on the same time axis, which would be considered as a novel contribution of this article. Since one component of the curve decreases (due to treatment) and the other component linearly increases (due to power generation), their combined value is expected to reach to a "minimum" oxygen case at a certain point. It can be, then, argued that the time point of the described minimum value essentially corresponds to the real efficient point of the closed loop system. Even though the treatment process may reach to lower COD levels for longer treatment times, the marginal COD gain would become not worth the additional oxygen demand requirement due to used energy.

The above described situation is exemplified on a high energy-consuming electrochemical treatment case of vinegar production wastewater treatment. Effects of varying the electrode types and initial $\mathrm{pH}$ values are also investigated and reported.

\section{Materials and Methods}

\subsection{Sample Acquisition and Experimental Set-Ups}

Electrochemical treatment experiments were conducted over real Vinegar Production Plant wastewater samples that were obtained from a large factory in Eskişehir. The samples were collected in polypropylene bottles and stored in a refrigerator at $277 \mathrm{~K}$ until experiments (on par with ISO 5667-1, 2007; EN ISO 5667-1/AC, 2007; ISO 5667-3:2012; ISO 5667-10: 2002 standards). The wastewater samples were measured to have a COD value of about $11000 \mathrm{mg} / \mathrm{L}$, a conductivity of close to $1.80 \mathrm{mS} / \mathrm{cm}$ and an initial $\mathrm{pH}$ value near to 4. Due to its particular restrictions, the initial COD values were diluted to around $2000 \mathrm{mg} / \mathrm{L}$ for the iridium coated electrode utilization.

The COD determination was achieved using prepared potassium di-chromate $\left(\mathrm{K}_{2} \mathrm{Cr}_{2} \mathrm{O}_{7}\right)$, acidic silver-sulfate solution, sulfuric acid solution $\left(\mathrm{H}_{2} \mathrm{SO}_{4}\right)$, and iron aluminum sulfate solution $\left[\left(\mathrm{NH}_{4}\right)_{2} \mathrm{Fe}\left(\mathrm{SO}_{4}\right)_{2} \cdot 6 \mathrm{H}_{2} \mathrm{O}\right]$ as a titrant. In order to improve conductivity, the support electrolyte of sodium sulfate $\left(\mathrm{Na}_{2} \mathrm{SO}_{4}\right.$, Merck) was also used. The $\mathrm{pH}$ value was adjusted using sodium hydroxide ( $\mathrm{NaOH}$, Merck).

Apart from the constructed reactor cabin, the experiments also required the utilization of an electrical power supply (STATRON, type 3262), a multimeter (Fluke 26-III model), stirrer (IDL, Hotplate Stirrer), peristaltic pump (Materflex L/S, model 7518-00), analytic weight scale (OHAUS, Explorer Pro), $\mathrm{pH}$ - and conductance-meter (Thermo Scientific Orion STAR A215), centrifugator (Nüve NF 800 R) and thermos-reactor (Merck Spectroquant TR 420.

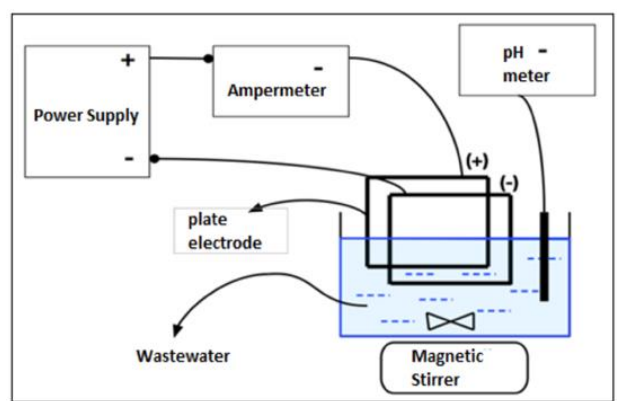

(a)

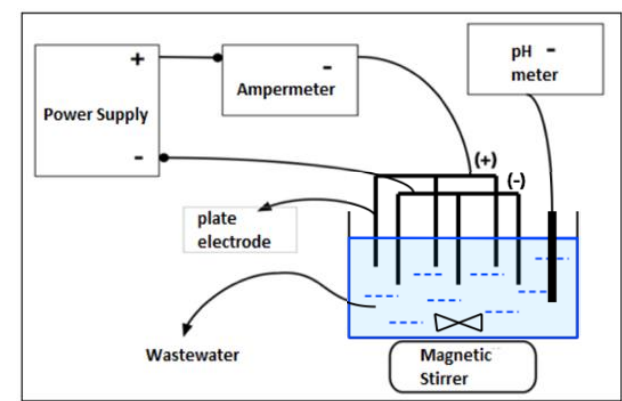

(b)

Fig. 1. Parallel plate electrochemical treatment set up illustrations for (a) iridium coated and (b) iron plate electrodes. 
Two types of electrodes were used: iron and iridium, both in the parallel-plate form. The iron electrode structure consisted of 6 plates that provides a surface area of $100 \mathrm{~cm}^{2}$. Iridium coated plate version had two plates, making a smaller surface area. In order to reduce plate worn-out and oxidation on the surfaces, occasional polarity switching was applied. The resulting reactor for iridium electrodes and iron electrodes are briefly illustrated in Figures 1 and 2, respectively.

\subsection{Electrochemistry}

Corresponding to the type of the electrode, two different electrochemical reactions occur in the treatment tank. Electro-coagulation happens when iron electrodes are used according to the following reactions.

At the anode side:

$$
\begin{aligned}
& 4 \mathrm{Fe} \rightarrow 4 \mathrm{Fe}^{+2}+8 \mathrm{e}^{-} \\
& 4 \mathrm{Fe}^{+2}+10 \mathrm{H}_{2} \mathrm{O}+\mathrm{O}_{2} \rightarrow 4 \mathrm{Fe}(\mathrm{OH})_{3}+8 \mathrm{H}^{+} \\
& \text {At the cathode side: } \\
& 8 \mathrm{H}^{+}+8 \mathrm{e}^{-} \rightarrow 4 \mathrm{H}_{2} \\
& \text { making an overall eqation of : } \\
& 4 \mathrm{Fe}+10 \mathrm{H}_{2} \mathrm{O}+\mathrm{O}_{2} \rightarrow 4 \mathrm{Fe}(\mathrm{OH})_{3}+4 \mathrm{H}_{2}
\end{aligned}
$$

Detailed explanations of the electro-coagulation process can be found in [13, 14].

When the iridium coated electrodes are used, an oxidation process occurs. The equations for this process is same for various metals including $\mathrm{Ti}, \mathrm{Pt}, \mathrm{Ru}, \mathrm{Pb}, \mathrm{Sn}$, etc. Using a common metal oxide notation: $\mathrm{MO}_{\mathrm{x}}$, the equations start by forming oxidization of organic matter and producing hydroxyl radicals:

$$
\mathrm{MO}_{\mathrm{x}}+\mathrm{H}_{2} \mathrm{O} \rightarrow \mathrm{MO}_{\mathrm{x}}\left(\mathrm{OH}^{-}\right)+\mathrm{H}^{+}+\mathrm{e}^{-}
$$

The hydroxyl radical is absorbed on the electrode surface and organic matter decays:

$\mathrm{R}+\mathrm{MO}_{\mathrm{x}}(\mathrm{OH})_{\mathrm{z}} \rightarrow(\mathrm{z} / 2) \mathrm{O}_{2}+\mathrm{zH}^{+}+2 \mathrm{e}^{-}+\mathrm{MO}_{\mathrm{x}}$

Again, details of the process can be reached from [14-17].

Performance differences of these two reactions will be illustrated and discussed in the experimental results section.

\subsection{Electrical energy production equivalent oxygen demand}

In order to convert the consumed energy $(\mathrm{kWh})$ into the demanded oxygen amount for the energy generation process, energy generation profile of the country must be investigated. In general, a combination of various electric power sources contributes to the overall electric supply. Each electric plant has its own $\mathrm{CO}_{2}$ emission per-kWh. The overall $\mathrm{CO}_{2}$ emission can be evaluated using the available ratios of each generator plant type [18]. Even for non-fossil fuel based electric generation systems (such as hydro-electric plants, nuclear plants and renewable energy plants), an equivalent emission rate has been evaluated [19, 20]. The most current $\mathrm{CO}_{2}$ emission averages per-kWh can be obtained from public reports of EIA, WEA or IEA [21-23]. A recent electrical energy source distribution study regarding the situation in Turkey can be found in [12]. According to these most recent studies (2012), the shares of each generator type and their contribution amounts are given in Table 1 . These rates are not expected to wildly change within the near future. Taking all these energy contributors into account and from the efficiencies of each source, the equivalent $\mathrm{CO}_{2}$ emission per $\mathrm{kWh}$ can be obtained as $0.534 \mathrm{~kg}$. As a comparison, the same $\mathrm{CO}_{2}$ emission in USA is around $0.600 \mathrm{~kg} / \mathrm{kWh}$ (according to EIA reports). 
Table 1. Distribution of Turkey's electric energy generation in 2012.

\begin{tabular}{|c|c|c|}
\hline Source & Amount (MW) & Ratio \\
\hline Hydroelectric & 19620 & 34 \\
\hline Natural Gas & 17164 & 30 \\
\hline Coal & 12395 & 22 \\
\hline Wind & 2261 & 4 \\
\hline Other & 5902 & 10 \\
\hline
\end{tabular}

Using the molecular mass formula, it can be easily seen that $32 / 44$ of the $\mathrm{CO}_{2}$ mass corresponds to oxygen. By calculation:

$$
N=0.534 \times 32 / 44=0.388 \mathrm{~kg} / \mathrm{kWh}=388 \mathrm{~g} / \mathrm{kWh} \text { of oxygen }
$$

in mass per consumed energy for the treatment (in Turkey). This rate can be compared with the values of energy consumption that we have obtained in our experiments.

\section{Experimental results}

The first set of experiments were conducted using an iron electrode as described above. The first comparison was for the effect of electrical current densities at the original (raw) $\mathrm{pH}$ value of 4.11. A detailed plot is provided in Figure 2, where the COD values at the treatment side is drawn blue and the equivalent oxygen demand of the electrical energy production is drawn red. It can be seen that their sum (shown in green) does not necessarily decrease in time.

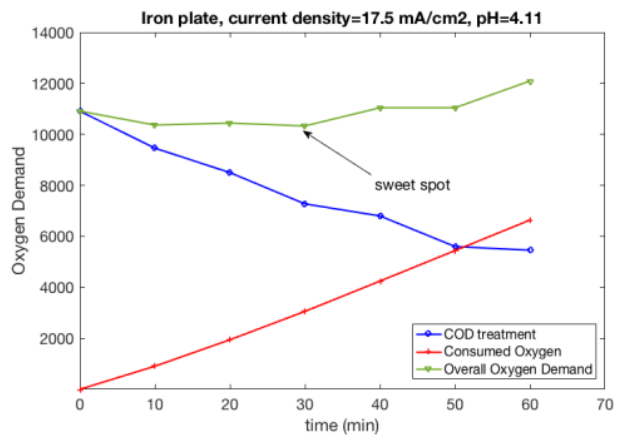

Fig. 2. Oxygen demands on the treatment (blue) and energy generation (red) sides with a total oxygen demand (green) plot using iron plate electrodes, $17.5 \mathrm{~mA} / \mathrm{cm}^{2}$ current density and $\mathrm{pH}=4.11$.

The overall increase starts at $30 \mathrm{~min}$ and any further process causes an overall oxygen demand of higher amounts. For a compact comparison of the eventual situation, the electrode configuration is tested further at $20 \mathrm{~mA} / \mathrm{cm}^{2}$ and $22.5 \mathrm{~mA} / \mathrm{cm}^{2}$ at the same $\mathrm{pH}$ of 4.11 in Figure 3(a). It can be seen that the better efficiency is achieved at $22.5 \mathrm{~mA} / \mathrm{cm}^{2}$. Therefore, at that electrical current density the effect of $\mathrm{pH}$ level was observed in Figure 3(b) by altering the initial $\mathrm{pH}$ value from 4.11 to 7 and 9 .

From Figure 3(b), it can be seen that alkalinity positively effects the treatment efficiency, where lower overall COD values could be achieved without contributing much oxygen demand for its energy consumption. Numerically, with the iron electrode, the lowest COD was achieved as $700 \mathrm{mg} / \mathrm{L}$ at the end of 60 minutes with a current density of $22.5 \mathrm{~mA} / \mathrm{cm}^{2}$ and a starting $\mathrm{pH}$ of 9 . The contribution of oxygen demand due to the utilized electricity was $5930 \mathrm{mg}$. Yet, the overall oxygen demand goes down from 11200 to 6630. 


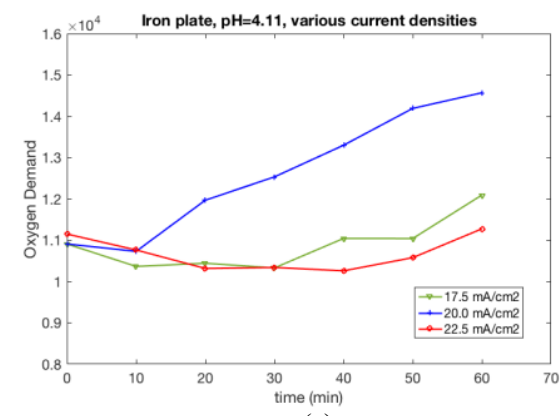

(a)

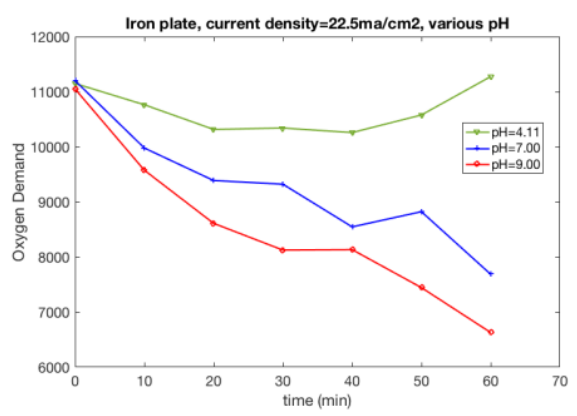

(b)

Fig. 3. Total oxygen demands of the operation with (a) $\mathrm{pH}=4.11$ and varying current densities, and (b) current density $=22.5 \mathrm{~mA} / \mathrm{cm}^{2}$ and varying $\mathrm{pH}$ values.

The experimental results for iridium coated electrodes show that these settings were clearly more inefficient in terms of energy, hence the oxygen cost for the electricity generation immediately invalidates the marginal COD reduction. After conducting experiments at various current densities and various $\mathrm{pH}$ values, the best results were achieved at a current density of $50 \mathrm{~mA} / \mathrm{cm}^{2}$ at the original $\mathrm{pH}$ value of 4.03 (as shown in Figure 4).

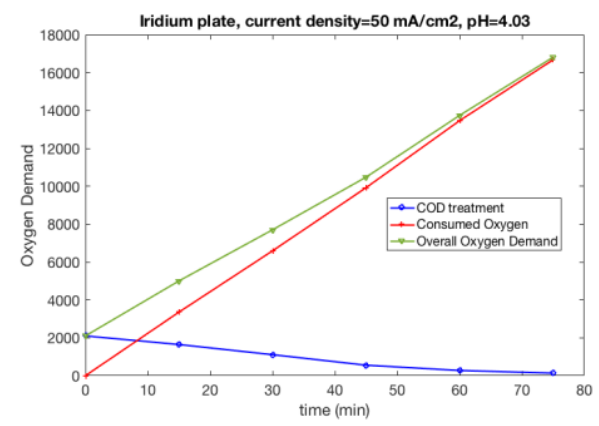

Fig. 4. Oxygen demands on the treatment (blue) and energy generation (red) sides with a total oxygen demand (green) plot using iridium plate electrodes, $50 \mathrm{~mA} / \mathrm{cm}^{2}$ current density and $\mathrm{pH}=4.03$.

It can be seen that the overall oxygen cost curve (green) starts to immediately increase. Numerically, the initial COD was $2100 \mathrm{mg} / \mathrm{L}$, and at the end of 75 minutes, the COD reduces to $137 \mathrm{mg} / \mathrm{L}$ whilst the required energy was $43 \mathrm{kWh} / \mathrm{m} 3$, corresponding to an oxygen consumption of $16672 \mathrm{mg}$ !

\section{Conclusions and discussions}

Despite the popularity of electrochemical treatment of wastewaters, the focus on the energy cost was limited to the economical aspects of the overall treatment [4-7]. Unfortunately, the economic cost of energy production (and consumption, thereof) is not directly compatible with the environmental impact of the direct and indirect wastes. The direct waste for this particular work is the wastewater of an actual vinegar production factory in Eskişehir. The impact of the wastewater is measured in terms of the COD. Using a novel approach to compare the reduction of COD in the wastewater to the average oxygen consumption during electric energy generation, a combined oxygen effect is obtained. The contributors can be plotted on the same time axis, and can be added to assess the overall oxygen demand (as in Figures 2-4). It is concluded that the treatment process should normally continue 
until the minimum cumulant oxygen demand is achieved (a time point, where the oxygen demand starts to increase). Some electrode types (e.g., iridium coated) are too inefficient even to start the electrochemical treatment process. Sadly, many of the energy consumption values reported in $[1-7,9,10]$ as compared to the reduced COD values are even higher than the energy consumption values reported herein. In order to constitute a valid and reasonable environmental effectiveness, the following are proposed:

- The regulation COD limits of certain wastewaters are arbitrarily set, and they do not take into account the treatment effect. The new limits must be achieved as a result of such studies.

- The best electrode, $\mathrm{pH}$ and current densities must be studied prior to applying electrochemical treatment in industrial plants.

- If electrochemical processes are a necessity, a real treatment plant MUST use local renewable electric generation systems, and the treatment process must not use grid electricity. In that case, the oxygen cost of electricity generation would become technically zero.

- The proposed novel "oxygen denominator" approach must be tested over various other wastewater types as further studies.

This research is funded by Anadolu University Research Fund under contract no: $1601 F 026$.

\section{References}

1. C. Barrera-Diaz, G. Roa-Morales, L. Avila-Cordoba, T. Pavon-Silva, B. Bilyeu, Ind. \& Eng. Chem. Res. 45, 1, 34-38 (2006)

2. G. Guven, N.A. Perendeci, K. Ozdemir, A. Tanyolac, J. Chem. Tech. 87, 4 (2012)

3. M. Panizza, P.A. Michaud, G. Cerisola, C. Comninellis, Electrochem. Comm. 3, 7, 336-229 (2001)

4. M. Kobya, E. Demirbas, J. Water Process Eng. 8, 64-74 (2015)

5. B.K. Korbahti, K.M. Turan, J. Turkish Chem. Soc. 3, 3, 75-92 (2016)

6. E. Demirbas, M. Kobya, Proc. Safety \& Env. Prot. 105, 79-90 (2017)

7. S.T. Lokendra, P. Mondal, J. Env. Mgmt. 190, 102-112 (2017)

8. E.E. Gerek, S. Y1lmaz, A.S. Koparal, O.N. Gerek, Int. Conf. Sust. Water Proc., Sitges, Spain (2016)

9. M.Z. Justin, D. Vrhovsek, A. Stuhlabacher, T.G. Bulc, Desalination 1, 6, 100-109 (2009)

10. P.J. Strong, J.E. Burgess, Bioremediation J. 12, 2, 70-87 (2008)

11. Woodard \& Curran, Inc., Ch. 7 - Industrial Waste Treatment Handbook, Second Ed. 149-334 (2006)

12. Ü.B. Filik, T. Filik, O.N. Gerek, Handbook of Clean Energy Systems, 4, 9, 1981-1995 (2015)

13. E. Butler, Y-T. Hung, T. Yeh, M.S. Al Ahmad, Water 3, 495-525 (2011)

14. C. Comninellis, G. Chen, G. (Ed.'s), Electrochemistry for the Environment (Springer, 2010)

15. D. Rajkumar, K. Palanivelu, N. Mohan, J. Env. Sci. \& Health, Part A: Tox/Hazard. Subst. Environ. Eng. 36, 19, 1997-2010 (2001)

16. C. Chen, A.J. Bloomfield, S.W. Sheehan, Ind. Eng. Chem. Res. (to appear, 2017) 
17. C.A. Martinez-Huitle, D.C. de Moura, D.R. da Silva, Chem. Eng. Trans. 41, 373-378 (2014)

18. E.H.S. Ralph, H-H. Rogner, K. Gregory, Energy Policy 31, 13, 1315-1326 (2003)

19. B.K. Sovacool, Energy Policy 36, 8, 2950-2963 (2008)

20. X. Varun, I.K. Bhat, R. Prakash, Energy Policy 13, 5, 1067-1073 (2009)

21. US Energy Information Administration: How much carbon dioxide is produced per kilowatthour when generating electricity with fossil fuels?, Online at: https://www.eia.gov/tools/faqs/faq.cfm?id=74\&t=11

22. World Energy Assessment, United Nations Development Programme (UNDP), UN Department of Economic and Social Affairs (UNDESA) and World Energy Council (WEC) Joint Report, NewYork, USA (2000)

23. International Energy Agency (IEA) report, Online at https://www.iea.org 